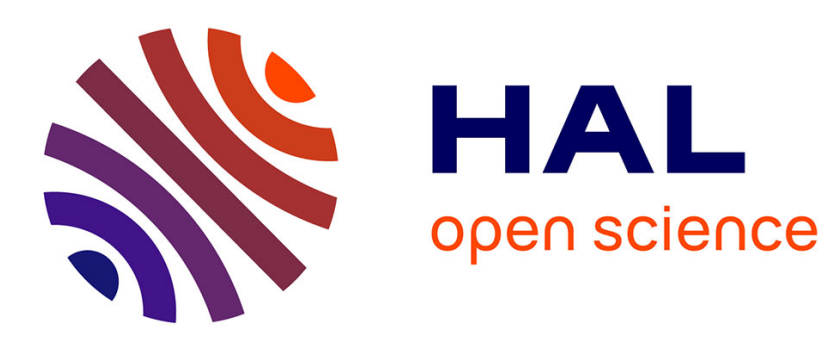

\title{
Meso-scale investigation of failure in the tensile splitting test: Size effect and fracture energy analysis
}

\author{
N. Benkemoun, Ph. Poullain, H. Al Khazraji, M. Choinska, A. Khelidj
}

\section{To cite this version:}

N. Benkemoun, Ph. Poullain, H. Al Khazraji, M. Choinska, A. Khelidj. Meso-scale investigation of failure in the tensile splitting test: Size effect and fracture energy analysis. Engineering Fracture Mechanics, 2016, 10.1016/j.engfracmech.2016.09.005 . hal-01380343

\section{HAL Id: hal-01380343 \\ https://hal.science/hal-01380343}

Submitted on 12 Oct 2016

HAL is a multi-disciplinary open access archive for the deposit and dissemination of scientific research documents, whether they are published or not. The documents may come from teaching and research institutions in France or abroad, or from public or private research centers.
L'archive ouverte pluridisciplinaire HAL, est destinée au dépôt et à la diffusion de documents scientifiques de niveau recherche, publiés ou non, émanant des établissements d'enseignement et de recherche français ou étrangers, des laboratoires publics ou privés. 


\title{
Meso-scale investigation of failure in the tensile splitting test: size effect and fracture energy analysis
}

\author{
Benkemoun N. ${ }^{a, *}$, Poullain Ph. ${ }^{a}$, Al Khazraji H. ${ }^{a}$, Choinska M. $^{a}$, Khelidj A. ${ }^{a}$ \\ a Université Nantes Angers Le Mans (L'UNAM), GeM, \\ Research Institute of Civil Engineering and Mechanics, CNRS UMR 6183, Nantes University, IUT \\ Saint-Nazaire \\ 58 rue Michel Ange, 44600 Saint-Nazaire, FRANCE
}

\begin{abstract}
In this paper, a meso-scale analysis is performed (1) to study the size effect on the nominal stress at failure and, (2) to quantify the evolution of the fracture process zone (FPZ) in the context of the tensile splitting test. The meso-structure is based on a two-phase 3D representation of heterogeneous materials, such as concrete, where stiff aggregates are embedded into a mortar matrix. In order to take into account these heterogeneities without any mesh adaptation, a weak discontinuity is introduced into the strain field. In addition, a strong discontinuity is also added to take into account micro-cracking. This model is cast into the framework of the Enhanced Finite Element Method (E-FEM). Based on the Finite Element simulations, size effect on the nominal stress at failure is numerically investigated and then compared to the so-called Bažant size effect law. In addition, an analysis based on the spatial distribution of the fracture energy is also regarded, leading to the 3D representation of the FPZ and to its volume value estimation.
\end{abstract}

Keywords: Tensile splitting test; Meso-scale modelling; Size effect law; Fracture energy;

Finite Element Method

\section{Introduction}

Like all brittle-type failure of concrete, tensile splitting test failure can be expected to exhibit a size effect. In general, size effect is studied in terms of nominal stress at failure $\sigma_{N}$

\footnotetext{
* Corresponding author.

Email address: nathan. benkemoun@univ-nantes.fr (Benkemoun N.)
} 
versus size of the specimen. On one hand, the experimental works of Lundborg et al. [1],

5 Sabnis et al. [2], Hasegawa et al. [3], Chen et al. [4] and Ross et al. [5] all stress that the tensile splitting test strength depends on a characteristic dimension chosen as the cylinder diameter. On the other hand, as pointed out in Bažant [6], this size effect on the nominal stress can be approximately described by the so-called Bažant size effect law:

$$
\sigma_{N}=\frac{B f_{t}}{\sqrt{1+\beta}}
$$

where $\sigma_{N}$ is the nominal stress at failure, $f_{t}$ is a strength parameter - for instance the direct

tensile strength -, $\beta$ is the brittleness number equals to $\frac{d}{d_{o}}, B$ and $d_{o}$ are empirical parameters and, $d$ a characteristic dimension of the specimen (cylinder diameter for the tensile splitting test). This law represents a gradual transition from the yield criterion at small sizes $(\beta \rightarrow 0)$, at which there is no size effect, to the case of linear elastic fracture mechanics (LEFM) at large sizes $(\beta \rightarrow \infty)$, at which the size effect is the strongest possible (see Fig. 1).

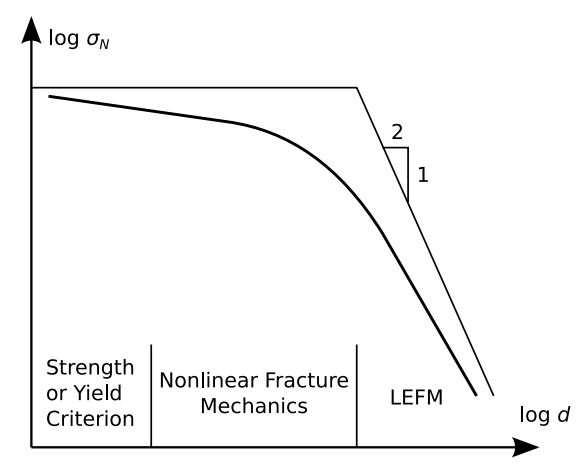

Figure 1: Bažant's size effect law $[\underline{6}]$

Nevertheless, in the context of the splitting tensile test, some researchers found some inadequacy when confronting the aforesaid experimental results with Bažant's size effect law. This inadequacy manifests itself through the appearence of an horizontal asymptote for large cylinder size in the experimental results that the Bažant's size effect law cannot reproduce. Tang et al. [7] pointed out that Bažant obtained his law only for notched specimens for which the notch size, seen as a flaw, was proportional to the characteristic dimension of the specimen. Consequently when applying the Bažant's size effect law to 
unnotched specimens - tensile splitting test cylinders for instance - the above hypothesis failed. The size of the characteristic flaw responsible for the crack propagation is in this case independent from the specimen size. Note that in Bažant and Yavari [8], the authors have derived a modification of eqn. (11) to take into account a size effect for unnotched specimen in the context of beam flexure.

In order to circumvent the aforesaid inadequacy in the context of the tensile splitting test, researchers have proposed different approaches. For instance, Bažant et al. [9] and Kim et al. [10] have derived modified size effect laws - based upon Bažant's size effect law - by incorporating functions $f$ monotonically decreasing with the ratio between the characteristic flaw size $a$ and the characterisitic dimension $d$ (diameter of the cylinder). In Bažant et al. [9], this decreasing is triggered by a threshold value of the characteristic dimension $d$ called $d_{t}$. Finally these modified size effect laws are capable to mitigate the downward trend of the size-effect curve - appearence of an horizontal asymptote for large cylinder size -, observed experimentally for the tensile splitting test [9] 1 . Unfortunately, it is very difficult to derive function $f(a / d)$ exactly. Carpinteri et al. 11] have recoursed to the concept of multifractality of the damaged material microstructure by means of the so-called multifractal scaling law (MFSL). They propose to analyse the size effect with the MFSL on the experimental tests of Hasegawa et al. [3] and Bažant et al. [9]. They obtain results in good agreement with these experimental tests even when the horizontal asymptote appears for large cylinder size 2 .

On the basis of the experimental results of Hasegawa et al. [3], another suggestion has been provided by Bažant [12] concerning the inadequacy of the Bažant's size effect law in the context of the tensile splitting test. The mode of failure might be shifted from brittle to ductile mechanism when large cylinder are encountered. Indeed for large cylinder and due to the size effect, the load peak producing this ductile mechanism of failure - through

\footnotetext{
${ }^{1}$ In fact a reversal of the size effect is even observed.

${ }^{2}$ Note that it is not the concern of this paper to debate which size effect law is the best between Bažant's size effect law and the multifractal scaling law developed by Carpinteri. For the readers interested in a confrontation of these two laws, see Bažant and Yavari [8].
} 
frictional plastic slip line 3 - could be reached before the splitting load peak. Consequently, because there is no size effect in ductile mechanism, an horizontal asymptote is observed in the size-effect curve - nominal stress at failure $\sigma_{N}$ versus size of the specimen - instead of a decreasing of the nominal stress as predicted by Bažant size effect law. This consideration leads to a formula still based on Bažant size effect law such as:

$$
\sigma_{N}=\frac{B f_{t}}{\sqrt{1+\beta}}+\sigma_{y}
$$

Finally, an alternative of the aforementioned argument is that the ductile mechanism develops only after the splitting load peak while considering that the load responsible of the ductile mechanism participates itself to the reach of the axial splitting load. In this case, the proposed formula takes the form:

$$
\sigma_{N}=\max \left(\frac{B f_{t}}{\sqrt{1+\beta}}, \sigma_{y}\right)
$$

In the last decades, a step forward has been made regarding the study of the size effect in concrete-like materials. Experimentally speaking, with the advent of displacement field measurement techniques such as digital image correlation (DIC, see Sutton et al. [13]), accessing to local quantities such as crack openings in volume of interest (VOI) became possible (see Corr et al. [14] for the original paper, Hild et al. [15] for the 3D extension of the method (digital volume correlation, DVC) and Oliver-Leblond et al. [16] for 3D deep reinforced concrete structures applications). Consequently these techniques allow to characterize for instance the size of the fracture process zone (FPZ) and its correlation with a characteristic dimension of a specimen. More recently, measures by acoustic emission (AE) techniques have proved their ability for visualizing and characterizing the FPZ in concrete-like materials (see Otsuka and Date [17] and Landis [18] for the pionneering work, Alam et al. [19] for a combined approach DIC/AE and Saliba et al. [20] for a study of creep-damage coupling in concrete). For instance, in Alam et al. [19], the authors quantify the length and the width of the FPZ in three notched beams (prepared in accordance with

\footnotetext{
${ }^{3}$ located in small highly confined wedge-shaped zone under the loading platens
} 
RILEM recomandations of size effect method). In Haidar et al. [21], the authors propose a correlation between the width of the FPZ measured by acoustic emission and parameters pertaining to the description of size effect such as $d_{0}$.

Numerically speaking, meso-scale models taking explicitely into account the microstructure of the specimen became more and more popular since the pioneering works of Schlangen and van Mier [22]. These models have demonstrated to be efficient in modelling important features of the behavior of concrete-like materials, not only for mechanical aspects (Wriggers and Moftah [23], Benkemoun et al. ([24], [25]), Pedersen et al. [26] and Roubin et al. [27]) but also for mass transport aspect (Jourdain et al. [28] and Nilenius et al. [29]). Concerning the aformentionned size effect, Grassl et al. [30] have proposed a meso-scale model based on the work of Bolander and Saito [31] combined to a damage mechanics model to:

1. determine the FPZ of concrete subjected to tension (see Grassl and Jirsek [30])

2. investigate the size effect on the FPZ and on the nominal stress at rupture in the context of (un)notched beams subjected to bending (see Grassl et al. [32] and Grégoire et al. [33]).

In Grassl et al. [30] and Grassl and Jirsek [32], the determination of the FPZ relies on the study of dissipated energy densities (see, Jirsek and Grassl [34]) of multiple analyses with randomly arranged aggregates leading to energy maps. Post-treatments of these maps are then performed in order to compare quantitatively the results for different geometries and levels of loading. Very recently, the community has been enlightened by the work of Grégoire et al. [35]. The authors propose to combine a numerical approach based on the model of Grassl et al. [30] and an experimental approach based on the acoustic emission (AE) technique in the context of (un)notched bending beams. They compare the energy maps for both the AE and the numerical model.

Based on the aforementionned litterature review, the objective of this work is to contribute to the understanding of fracture processes in the tensile splitting test by numerically investigating :

1. size effect on the nominal stress at failure 
2. the FPZ evolution. embedded into a mortar matrix. Consequently, the influence of the shape, the size, the distribution and the mechanical properties of aggregates - playing a significant role on the mechanical behavior of concrete (see Yaman et al. [36]) - is taken into account. Starting from this point, a 3D Finite Element analysis relying on the work of Benkemoun et al. [24] is conducted. First, size effect on the nominal stress at failure is regarded. We propose an approach where the characteristic dimension is the aggregates size rather than the size specimen as it is usually done in the litterature (see Bažant et al. [9] for instance). This choice is relevant regarding the non-adaptated meshing process (see Moës et al. [37]) retained to mesh the microstructure. Second, we aim at a better understanding of the FPZ evolution in the context of the tensile splitting test. In this sense, an analysis based on the spatial distribution of the fracture energy is derived. The volume of the FPZ $V_{F P Z}$ is thus determined from this fracture energy field and is here defined as the volume of the specimen inside which $95 \%$ of the total fracture energy is dissipated. We investigate a correlation between the FPZ volume value, the aggregates size and the level of cracking.

This paper is as follows : In Section 1, we give a brief description of the meso-scale mechanical model. Then we present the numerical results of the tensile splitting test and the investigation of the size effect on the nominal stress at failure. In Section 2, we present the fracture energy analysis of the tensile splitting test. In a first time, we detail the method conducted to perform this fracture energy analysis. In a second time, we present the numerical results concerning both the FPZ volume value and the FPZ width value computation. Finally a discussion concerning the correlation between the FPZ volume (width) value and the aggregate size is presented.

\section{Numerical investigation of the size effect in the tensile splitting test}

In this section, we give a brief description of the mechanical model. For the readers 110 interested in more details, a complete description of the model, its numerical implementation 
and a number of illustrative examples of the model predictive capabilities can be found in Benkemoun et al. [24].

\subsection{Meso-scale mechanical model}

The numerical model for the mechanical simulations is based upon a two-phase (stiff aggregates embedded into a mortar matrix) quasi-brittle model capable of representing the behavior of concrete-like materials under complex loading paths. In order to take into account the influence of the shape, the size, the distribution and the mechanical properties of aggregates on the mechanical behavior of concrete, the mesoscale (Wriggers and Moftah [23], Borja and Andrade [38]) is chosen to be the scale of computation. The numerical approach we work with, at the mesoscale, is based upon a 3D lattice finite element model (Schlangen and van Mier [22], Schlangen and Garboczi [39], Yip et al. [40] and Lachihab and Sab [41]) whose truss elements kinematics is enhanced by two discontinuities embedded in the elements.

The first discontinuity is a weak discontinuity - continuous displacement field and discontinuous strain field (Ortiz et al. [42]) - introduced because of the non-adaptated meshing process (Moës et al. [37]). This process consists in a unique homogeneous mesh whose nodes are placed independently from the morphology of the aggregates. A significant amount of computation time is saved at this stage. However, some truss elements are cut into two parts, each having different elastic properties (see Fig. 2 for a two-phase material). That's why in order to take into account this special kinematics in the truss elements, this weak discontinuity is introduced.

The second discontinuity is a strong discontinuity - discontinuous displacement field and unbounded strain field (Simo et al. [43]) - introduced in order to represent micro-cracks that may occur in any of different phases (aggregates or mortar matrix for two-phase materials) and to capture the interface failure (debonding). Moreover, the key point pertains to strong discontinuities capability to model softening behavior without any mesh dependency which is the major issue dealing with failure of quasi-brittle materials.

The weak discontinuity is present only for the truss elements split into two parts, each 


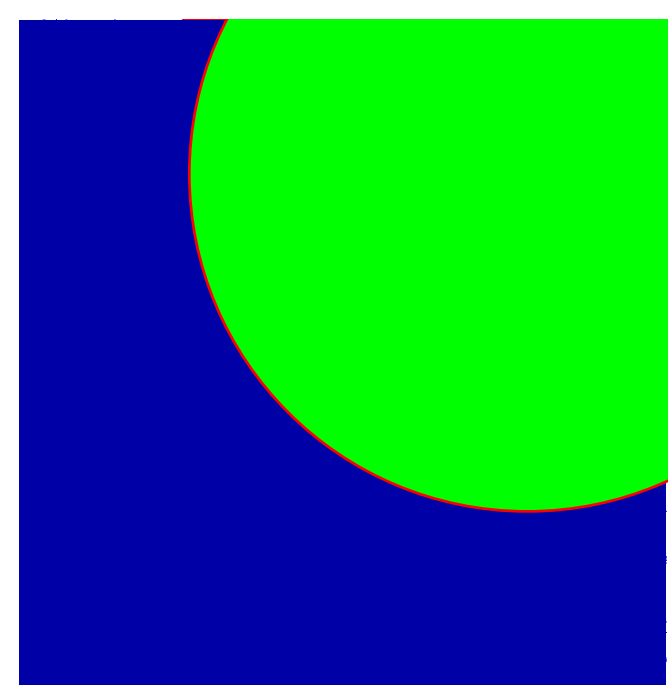

(a) Two-phase material

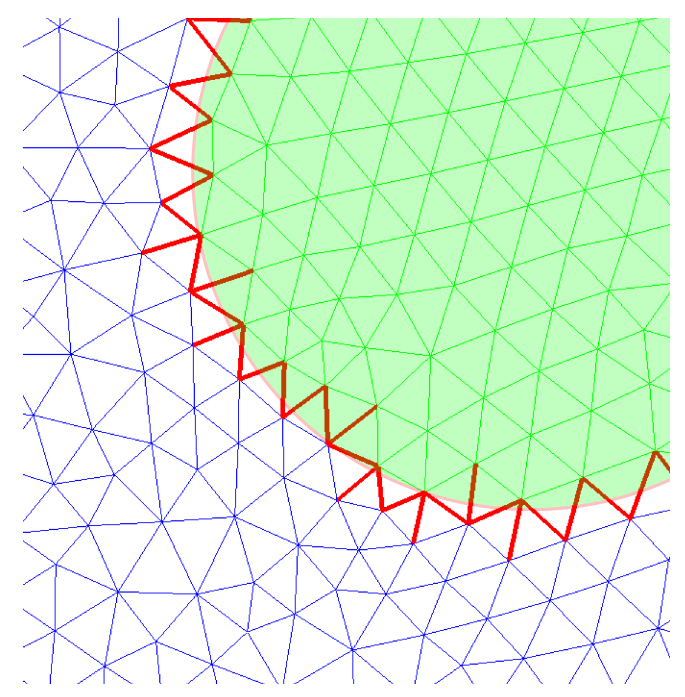

(b) Non-conforming mesh discretisation

Figure 2: Two-phase material example in 2D with the mortar matrix in blue, one aggregate in green and the interface in red. Non-conforming mesh discretisation gives three sets of truss elements: those entirely inside the matrix (in blue with no weak discontinuity activated), those entirely in the aggregate (in green with no weak discontinuity activated) and those split by a physical interface (in bold red) and for which the weak discontinuity is activated.

having a different Young modulus. The strong discontinuity is introduced by means of a yield function $g$ which is triggered only in traction. Thus two constitutive models appear for a truss element: a continuum one (outside the discontinuity) which is elastic (see Figure 3(a) , and a discrete one (over the discontinuity) which is quasi-brittle (see Figure 3(b)). We denote by $t_{\Gamma}$ the traction vector over the discontinuity and $[|u|]$ the crack width which belongs to the set of unknowns.

The yield function is such as:

$$
g=t_{\Gamma}-\left(\sigma_{u}-q\right)
$$

where $q$ is the stress-like variable

$$
q=\mathrm{k}([|u|]) ; \mathrm{k}([|u|])=\sigma_{u}\left(1-\exp \left(-[|u|] \frac{\sigma_{u}}{G_{f}}\right)\right) .
$$

In summary, there are altogether eight model parameters: the Young modulus $E^{\oplus}$ for the mortar matrix and $E^{\ominus}$ for aggregates, for the continuum model and the ultimate tensile 


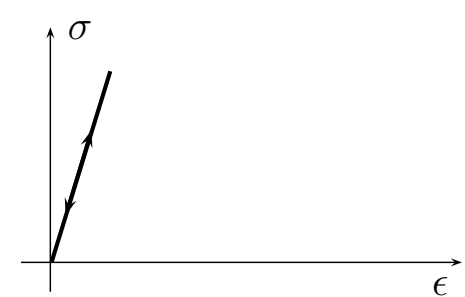

(a) behavior outside the discontinuity

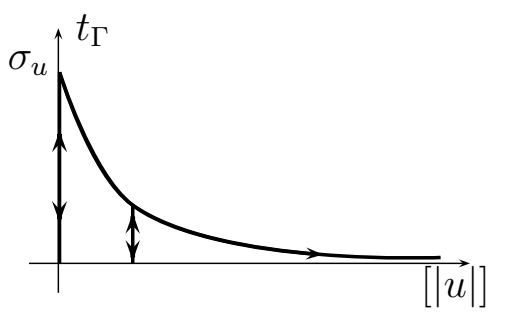

(b) behavior over the discontinuity

Figure 3: Elastic-quasi-brittle behavior [25]

strength before softening, $\sigma_{u_{i}}$ and the fracture energy, $G_{f_{i}}(i=1,2,3$ for respectively the mortar matrix, aggregates and interfaces) for the discrete model. We note $G_{f_{i}}$ the area under the curve $t_{\Gamma}-[|u|]$.

Having at end the weak and strong discontinuities definition, we now turn to a short description of the mathematical framework and the solving procedure. The total strain is written in the context of the EAS (Enhanced Assumed Strain, [44]) method such as:

$$
\varepsilon=\underbrace{\boldsymbol{\nabla}^{s} \overline{\boldsymbol{u}}}_{\text {regular }}+\underbrace{\tilde{\varepsilon}}_{\text {weak }}+\underbrace{\hat{\varepsilon}}_{\text {strong }}
$$

where $\boldsymbol{\nabla}^{s} \overline{\boldsymbol{u}}$ is the symmetric gradient of the displacement field. As in Simo and Rifai [44], we refer to $\tilde{\varepsilon}$ and $\hat{\varepsilon}$ as the enhanced parts of the strain field. The notation $\tilde{\bullet}$ (resp. $\hat{\bullet}$ ) refers to weak (resp. strong) discontinuity.

In the context of a truss element, $\tilde{\varepsilon}$ and $\hat{\varepsilon}$ have the following form:

$$
\tilde{\varepsilon}=\boldsymbol{G}_{\mathrm{w}}^{\oplus / \ominus}[|\epsilon|] \text { and } \hat{\varepsilon}=\boldsymbol{G}_{\mathrm{s}}[|u|]
$$

where $\boldsymbol{G}_{\mathrm{w}}^{\oplus / \ominus}$ and $\boldsymbol{G}_{\mathrm{s}}$ are enhanced functions. [| $\left.\mid\right]$ and $[|u|]$ are the enhanced interpolation parameters and belong to the set of unknowns.

This strain field (equation (6) ) is then introduced in the Hu-Whasizu-de Veubeke 1 variational formulation (Hu, [46], Washizu, [47] and de Veubeke, [48]) leading to the Finite Element problem to be solved in terms of the displacement field $\boldsymbol{d}$ and the enhanced interpolation parameters $[|\epsilon|]$ and $[|u|]$ for the weak and strong discontinuities, respectively. The

\footnotetext{
${ }^{1}$ Fraeijs de Veubeke: neglected discoverer of the "Hu-Washizu Functional", 45]
} 
solving procedure is achieved by a local-global solving process: $[|\epsilon|]$ and $[|u|]$ are computed by means of a return mapping algorithm (Simo and Hughes, [49]) and after a static condensation of $[|\epsilon|]$ and $[|u|]$ (Wilson, [50]), the displacement field $\boldsymbol{d}$ is computed for each iteration $k+1$ of a typical time step $n+1$.

In the next section, we present the numerical simulations of the tensile splitting test.

\subsection{Numerical simulations of the tensile splitting test}

We propose to simulate the tensile splitting test by means of the Finite Element model developed in Benkemoun et al. [24].

\subsubsection{Characteristic dimension d}

In the aformentionned tensile splitting tests litterature, the scale range of the cylinders diameter is in general very broad. In [9] it is 1:26 corresponding to tests conducted on cylinders with a diameter $=19,38,76,152,254$, and $508 \mathrm{~mm}$. In [3], it is 1:30. These ranges are broader than in any previous tests (never over 1:16) so it is not surprising that the limit of applicability of eqn. (1) has not been detected in the previous tests.

As we will see hereafter, in the context of the proposed numerical study, the scale range is quite narrrow (1:4). Consequently, in a first attempt, we consider that the cylinders size stay "far away" from the size where an horizontal asymptote appears. The assumption that eqn. (1) is still applicable is therefore justified. Eqn. (1) is thus considered for the numerical analysis of the size effect on the nominal stress at failure. Consequently, the characteristic dimension $d$ of the specimen has to be selected. Usually in the litterature (see [9] for instance) this characteristic dimension is chosen as the diameter $\Phi$ of the specimen. The size effect is therefore studied by increasing $\Phi$ and then computing $\sigma_{N}$. For instance, in [9], tests are conducted on cylinders of diameters $\Phi=19,38,76,152,254$, and $508 \mathrm{~mm}$.

In the proposed work, we investigate a slightly different method. Instead of choosing the cylinder diameter $\Phi$ as the characteristic dimension $d$, we consider the aggregate diameter $D$ as the characteristic dimension $d$. Consequently, tests are conducted on cylinders with a fixed diameter $\Phi$. Nevertheless, for each of these cylinders the aggregate diameter $D$ is increased. Five cylinders are tested, which geometrical characteristics are given in table 1. 


\begin{tabular}{cccccc}
\hline $\begin{array}{c}\text { Cylinder } \\
\text { id. }\end{array}$ & $\begin{array}{c}\text { Cylinder } \\
\text { diameter }[\mathrm{mm}]\end{array}$ & $\begin{array}{c}\text { Cylinder } \\
\text { thickness }[\mathrm{mm}]\end{array}$ & $\begin{array}{c}\text { Aggregate } \\
\text { diameter }[\mathrm{mm}]\end{array}$ & $\begin{array}{c}\text { Aggregate } \\
\text { volume fraction targeted }\end{array}$ & $\begin{array}{c}\text { Mesh figure } \\
\text { on }\end{array}$ \\
\hline$S_{1}$ & 110 & 50 & 4 & $20 \%$ & Fig. 5(a) \\
$S_{2}$ & 110 & 50 & 8 & $20 \%$ & Fig. 5(b) \\
$S_{3}$ & 110 & 50 & 10 & $20 \%$ & Fig. $5(\mathrm{c})$ \\
$S_{4}$ & 110 & 50 & 14 & $20 \%$ & Fig. 5(d) \\
$S_{5}$ & 110 & 50 & 16 & $20 \%$ & Fig. $5(\mathrm{e})$ \\
\hline
\end{tabular}

Table 1: Identification of the tested cylinders

We keep a constant volume fraction equals to $20 \%$ and the size range is 1:4. As stressed just before, due to the fact that the size range is narrow (1:4), the usual Bažant size effect law (eqn. (1)) can be considered for the size effect study.

Last but not least, in the context of non-adaptated meshing process (see [37]), the choice of the aggregates diameter as the characteristic dimension is relevant.

1. All the computations are performed with the same mesh, eliminating bias that could appear with different meshes and

2. because the aggregates are placed independently from the mesh, an important amount of computation time is saved.

Finally, as observed in Fig. 4, $\Phi$ and $D$ have an inverse role. The highest value of $D$ corresponds to the lowest value of $\Phi$ and the lowest value of $D$ corresponds to the highest value of $\Phi$. Consequently if we want to confront our size effect study to Bažant size effect law - in which the nominal stress at failure $\sigma_{N}$ decreases when the characteristic dimension increases - eqn. (1) has to be slightly modified considering $\beta$ now equals to $\frac{d_{o}}{D}$. In this sense, $1 / D$ and $\Phi$ now evolve with the same trend. Consequently the retained characteristic dimension is $1 / D$ for the numerical study in this paper.

\subsubsection{Finite Element simulations results}

The numerical simulations are performed by means of the meshes presented in Fig. 5. 


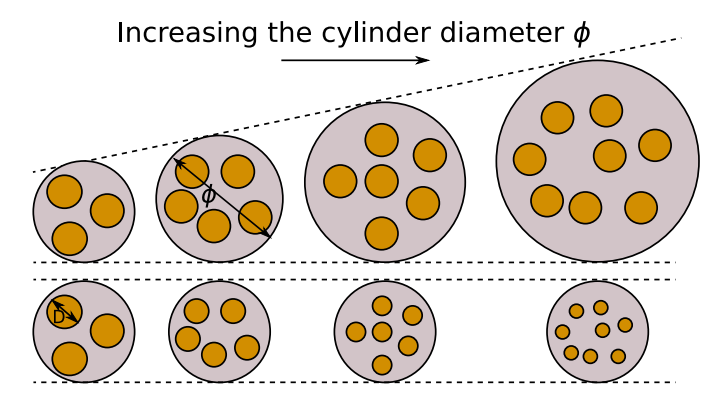

Decreasing the aggregate diameter $D$

Figure 4: Equivalence between the usual approach ([9] for instance) and the approach of this paper for the caracterisation of the size effect

for the different phases. Note that the aggregates are stiffer than the mortar matrix and remain in the elastic regime. The computation is made under displacement control at the top of the cylinder according to the second spatial axis $Y$.

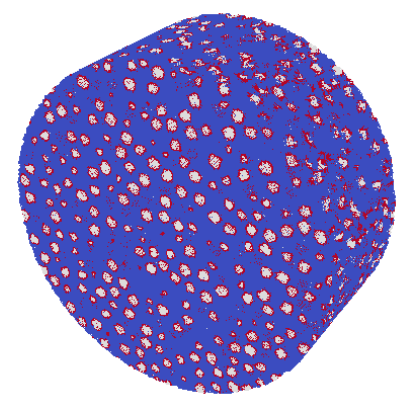

(a) $S_{1}$

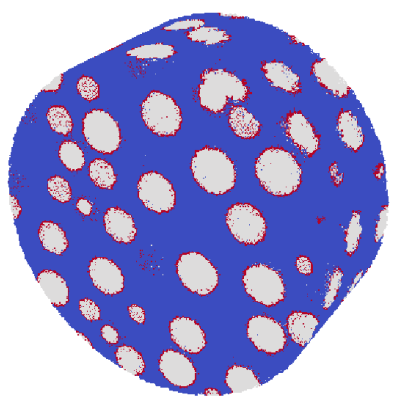

(d) $S_{4}$

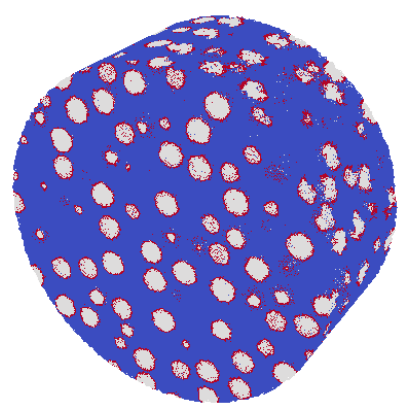

(b) $S_{2}$

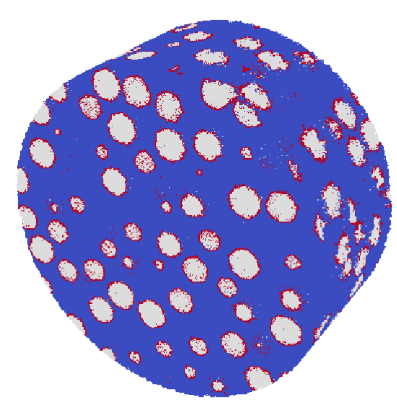

(c) $S_{3}$

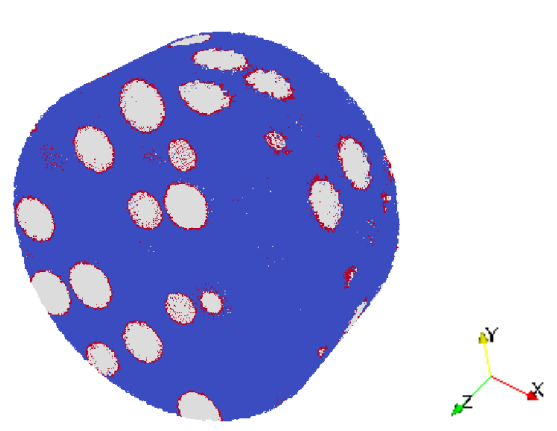

(e) $S_{5}$

Figure 5: Plot of the meshes for the numerical simulations. The volume fraction is constant and equal to $20 \%$ 


\begin{tabular}{cccc}
\hline phase & $E(G P a)$ & $\sigma_{u}(M P a)$ & $G_{f}\left(\mathrm{~J} / \mathrm{m}^{2}\right)$ \\
\hline mortar matrix & 35 & 3 & 80 \\
\hline aggregates & 100 & elastic & elastic \\
\hline interfaces & - & 3 & 80 \\
\hline
\end{tabular}

Table 2: Mesoscale material properties for the numerical simulations

Fig. 6 plots the macroscopic stress versus imposed displacement curves for each cylinder $S_{i}$. Three phases can be observed:

- Phase I (pre-peak region) where a non-linear macroscopic behavior is obtained. In this phase, diffuse crack (micro-cracks) are created in the mortar matrix and at the interfaces aggregates/mortar matrix.

- Phase II (peak at rupture region) where the macroscopic ultimate tensile strength $\sigma_{\max }$ is reached. In this phase, the coalescence of the micro-cracks lead to a macroscopic crack (localized crack).

- Phase III (post-peak at rupture region) where a softening macroscopic behavior is observed. In this phase, the deformation is mainly localized in the established macrocrack.

By computing the area under these macroscopic curves for each imposed displacement increment $\Delta \bar{u}$, we determine the cumulative total energy as shown in Fig. 7 . This total energy accounts for both the elastic energy and the dissipated energy through the fracture process.

Fig. 8 show the crack pattern at the end of the numerical simulations. It corresponds to the micro-cracked bar elements for which the strong discontinuity has been activated. As observed experimentally (see Fig. 9 for instance), we observe one macro-crack roughly located in the plane $Y-Z$ and passing around the aggregates. This macro-cracked is sufficient to drive the macroscale response into the softening regime (see Fig. 6). We note that the value of the maximum crack opening increases with the increase in the aggregate diameter. This result is also observed in some experimental papers such as [51] and [52]. 


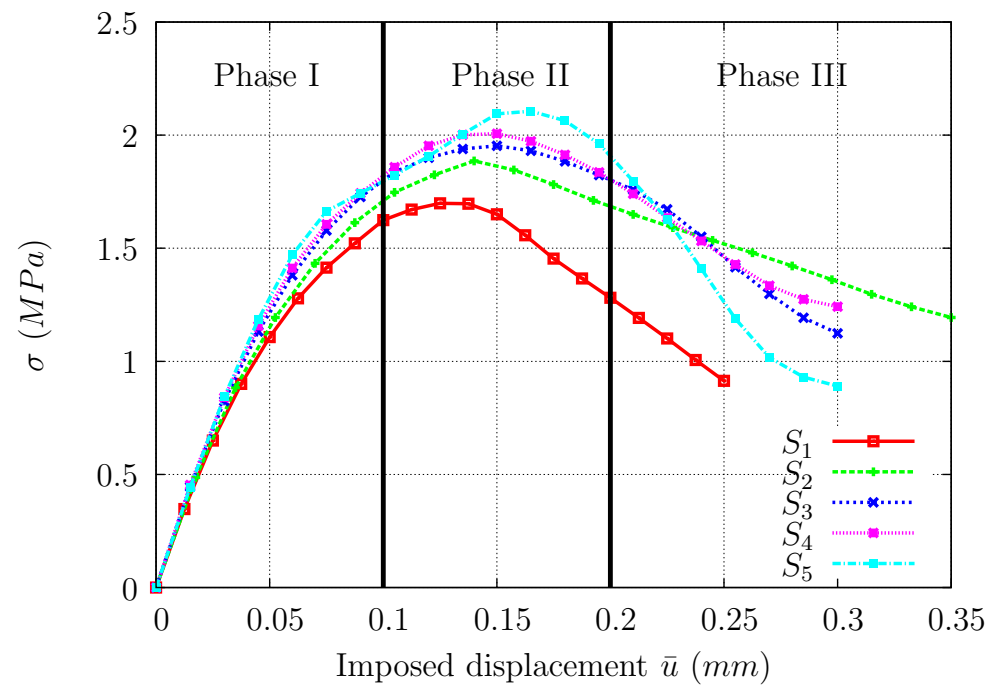

Figure 6: Macroscopic stress versus imposed displacement plots for each cylinder $S_{i}$

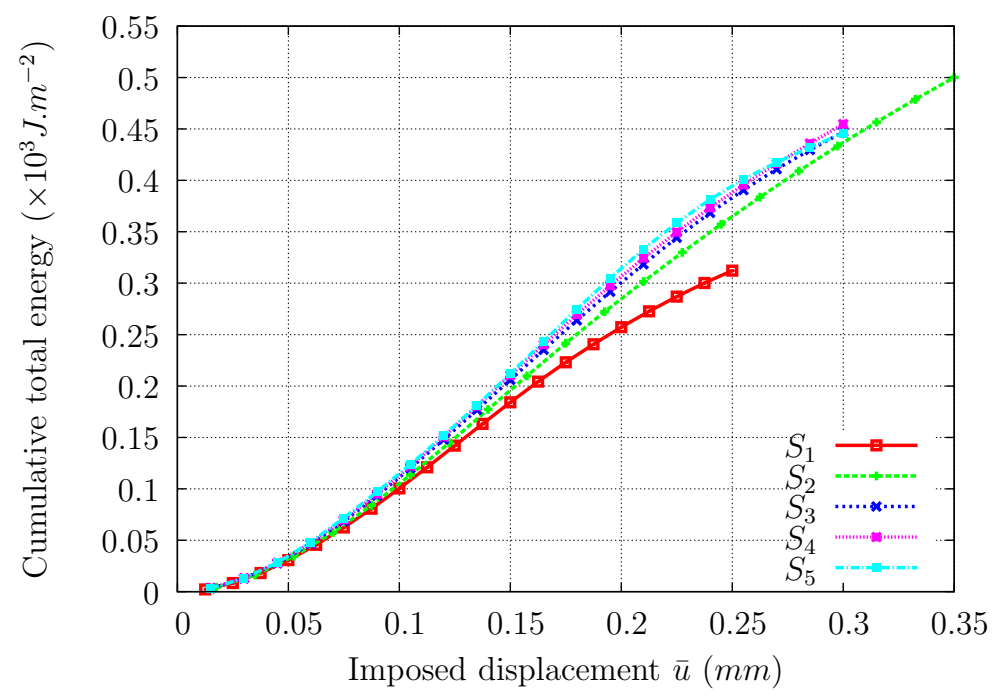

Figure 7: Cumulative total energy versus imposed displacement plots for each cylinder $S_{i}$

\subsection{Size effect in the tensile splitting test}

Table 3 sums up the numerical results in terms of nominal stress at failure $\sigma_{N}$ versus the characteristic dimension $1 / D$. We remind that $D$ is the aggregate diameter.

Regarding Table 3, we conclude that the value of $\sigma_{N}$ decreases when the characteristic dimension $1 / D$ increases. These results are in agreement with the trend observed in experimental results conducted in [3] and [9] : the nominal stress at failure decreases when the 


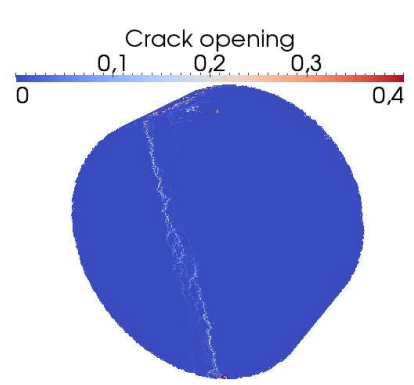

(a) $S_{1}$

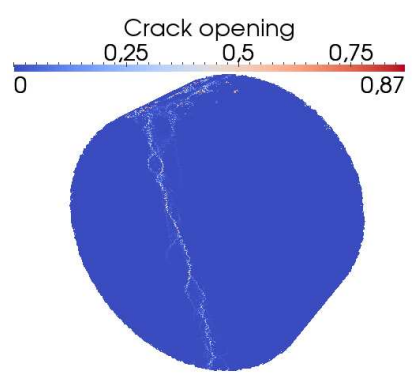

(b) $S_{2}$

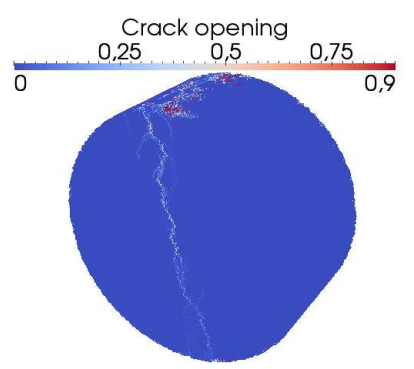

(c) $S_{3}$

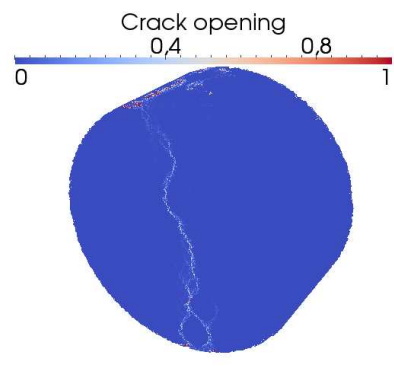

(d) $S_{4}$

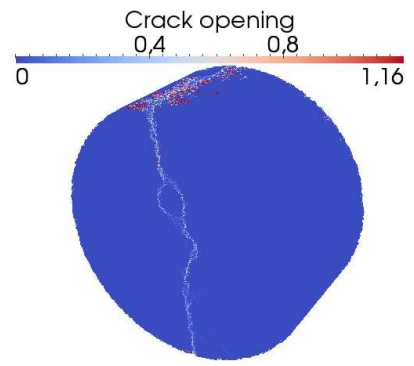

(e) $S_{5}$

Figure 8: Crack pattern at the end of the numerical simulations. Crack opening are given in $\mathrm{mm}$.

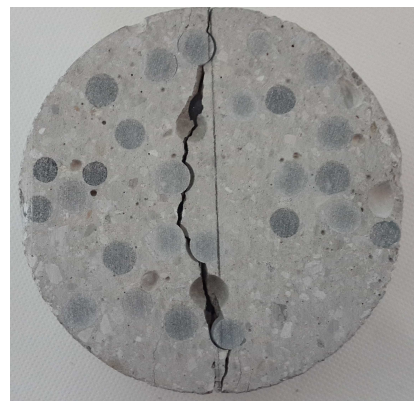

Figure 9: Experimental results of the tensile splitting test $(D=110 \mathrm{~mm}$ and $e=50 \mathrm{~mm})$.

\begin{tabular}{cccccc}
\hline Specimen & $S_{5}$ & $S_{4}$ & $S_{3}$ & $S_{2}$ & $S_{1}$ \\
\hline Char. dim. 1/D $\left(\mathrm{mm}^{-1}\right)$ & 0.0625 & 0.0714 & 0.1000 & 0.1250 & 0.2500 \\
\hline$\sigma_{N}(M P a)$ & 2.1100 & 2.0000 & 1.9530 & 1.9000 & 1.7000 \\
\hline
\end{tabular}

Table 3: Nominal stress at failure $\sigma_{N}$ from numerical simulations

characteristic dimension increases.

After rewritting the Bažant size effect law (eqn. (1)) with the modified $\beta=\frac{d_{o}}{D}$ and 
transforming it to a linear regression plot, we obtain:

$$
Y=A X+C
$$

with $Y=1 /\left(\sigma_{N}\right)^{2}, X=1 / D, C=1 /\left(B f_{t}\right)^{2}$ and, $A=C d_{o}$.

The linear regression plot of eqn. (8) is shown in Fig. 10, It is apparent that the results are in good agreement with the size effect law (eqn. (11)) with the modified $\beta=\frac{d_{o}}{D}$. The regression analysis yields $\mathrm{A}=0.5936 \mathrm{~mm}$ and $\mathrm{C}=0.1997$, from which $d_{o}=2.97 \mathrm{~mm}$ and $B f_{t}=2.24 \mathrm{MPa}$. The correlation coefficient of the regression is $\mathrm{r}=0.972$. Fig. 11 plots the $\log -\log$ version of Bažant size effect law with modified $\beta=\frac{d_{o}}{D}$ versus the numerical results. It is worth noting that the numerical results follow well the trend of Bažant size effect law and that no asymptotic behavior is observed. As stated before, this observation can be justifed by the narrow scale range (1:4).

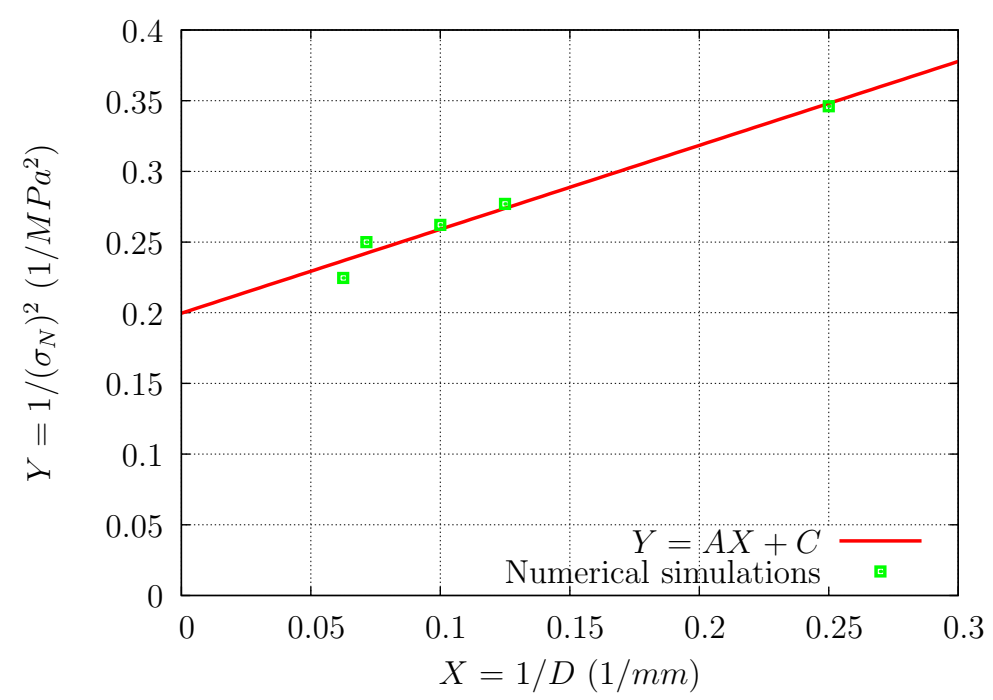

Figure 10: Bažant size effect law with modified $\beta=\frac{d_{o}}{D}$ versus numerical results (linear regression)

\section{Fracture energy analysis of the tensile splitting test}

In this Section, we introduce, first, the method conducted to perform the fracture energy analysis. Second, we discuss the numerical results obtained with the method. 


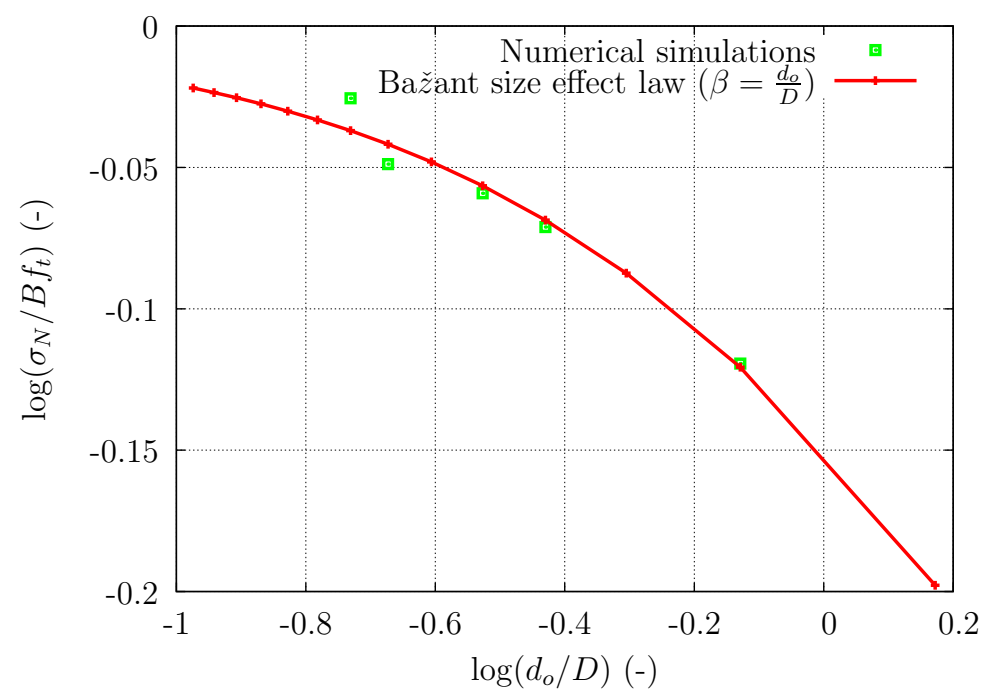

Figure 11: Bažant size effect law with modified $\beta=\frac{d_{o}}{D}$ versus numerical results (log-log version)

\subsection{Fracture energy analysis method}

The fracture energy is computed at the end of the mechanical Finite Element simulations. For each time step and each bar element, we calculate the fracture energy value as the area under the curve $t_{\Gamma}-[|u|]$ (see Fig. $3(\mathrm{~b})$ ). This fracture energy value is then set at the center $C$ of the corresponding bar element. Consequently, for each time step, a three dimensional set of points placed in a $(x, y, z)$ space is obtained with a fracture energy value associated to each of these points. The number of points is equal to the number of bar elements. The $(x, y, z)$ space is then discretized into a three dimensional grid of rectangular elements with uniform dimensions in order to perform the fracture energy analysis. We see here the fundamental role of the mechanical model furnishing the crack opening values for each bar element and, thus allowing to compute the fracture energy values.

We apply this method to the numerical simulations results obtained in Section 2.2. A statistical approach relying on an energy-based criterion is performed in order to determine the volume of the FPZ in relation with the aggregates size and the level of loading. The volume of the FPZ $V_{F P Z}$ is determined from the fracture energy field and is here defined as the volume of the specimen inside which $95 \%$ of the total fracture energy is dissipated (see the experimental work of Otsuka and Date [17]). The principle of the determination is 
described in Fig. 12,

To compute $V_{F P Z}$, the fracture energy field is first interpolated over a $200 \times 200 \times$ 40 three dimensional rectangular grid (see Grassl and Jirsek [30] for a similar approach in 2D). This grid corresponds to 1,600,000 rectangular elements. This size has been chosen in accordance to the number of bar elements $(1,584,958)$ in the meshes used for the Finite Element simulations and shown in Fig. 5. This interpolation allows the representation of fracture energy fields as shown in Fig. 13(a) for example.

Then, the fracture energy is cumulated along direction $x$, for the different values of $y$ and on each slice of the cylinder defined by the altitude $z$. This yields a curve showing the evolution of the relative cumulated fracture energy along $x$. The values of $x$ corresponding to a relative cumulated fracture energy of $2.5 \%\left(x_{\min }\right)$ and $97.5 \%\left(x_{\max }\right)$ then allow the determination of the width of the FPZ as a function of $y: L_{F P Z}(y)=x_{\max }-x_{\min }$. By integrating this function over $y$ for each slice, we obtain the total volume of the FPZ. This procedure is carried out for different time steps to determine the evolution of the volume of the FPZ for different imposed displacements.

\subsection{Numerical results discussion}

\subsubsection{FPZ volume value $\left(V_{F P Z}\right)$}

Fig. 13 plots the $2 \mathrm{D}$ representation of the fracture energy for $D=4,8,10,14$ and 16 $m m$ at the end of the computation. We show the results for cylinder slices located at the middle of the specimen $(Z=25 \mathrm{~mm})$. We distinguish the elastic aggregates colored in black - meaning that no fracture energy is dissipated - between the mortar matrix. We also see that the fracture energy is mainly dissipated in a band whose width varies in relation with the aggregates diameter.

Fig. 14 plots the evolution of $V_{F P Z}$ in relation with the imposed displacement for $D=$ 4, 8, 10, 14 and $16 \mathrm{~mm}$. In these curves, three phases can be observed (for a correspondance with the curves stress versus imposed displacement, see Fig. 6):

- Phase I where $V_{F P Z}$ rises rapidly in the pre-peak at rupture region. It is due to the increase in diffuse cracks (micro-cracks) density. These micro-cracks nucleate at the 


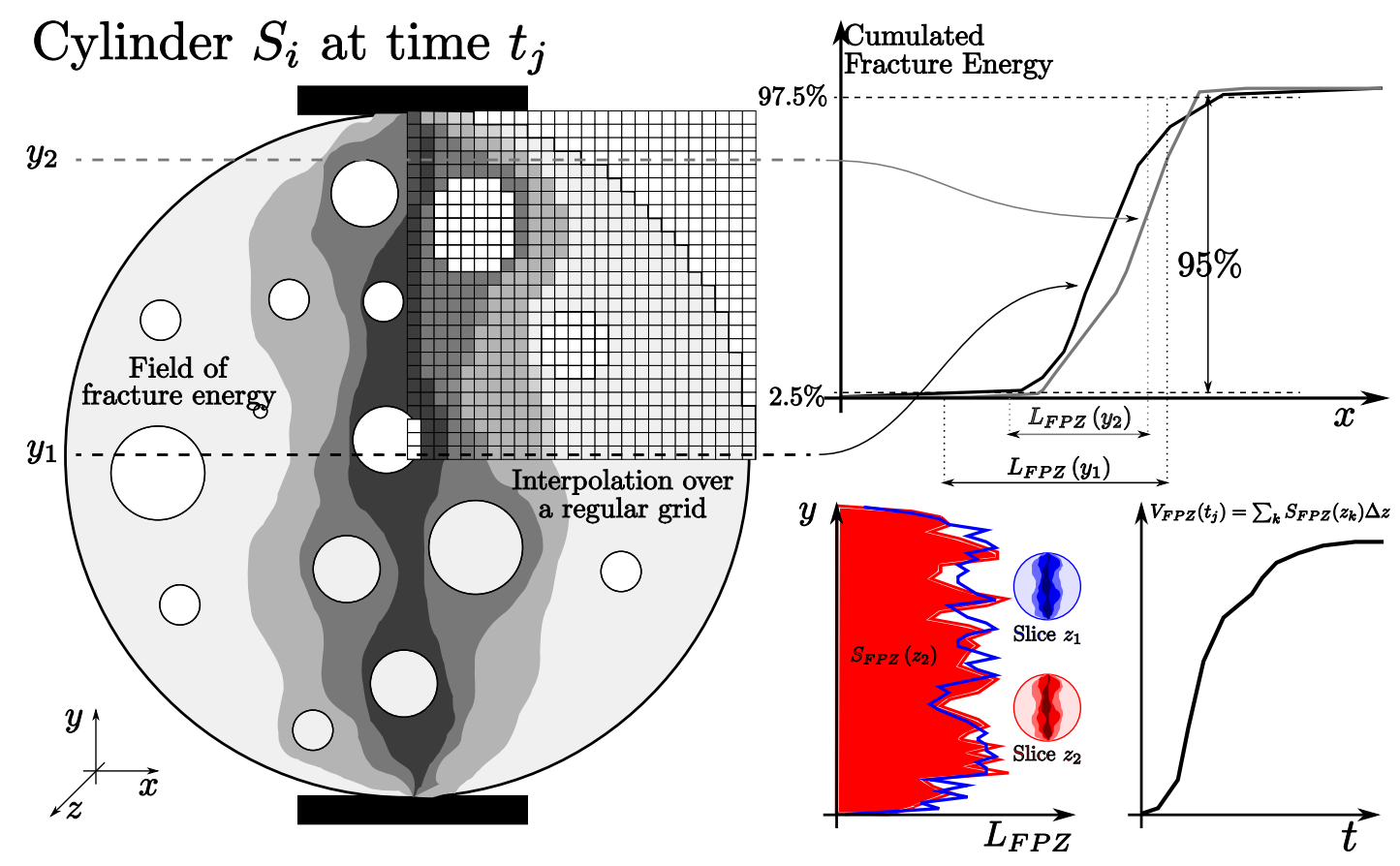

Figure 12: Determination of the volume of the FPZ $\left(V_{F P Z}\right)$

interfaces aggregates/mortar and then propagate in these interfaces and in the mortar matrix.

- Phase II where $V_{F P Z}$ rises slowly in the peak at rupture region. It is due to the coalescence of diffuse cracks (micro-cracks) leading to a localized crack (macro-crack). In this phase, the fracture energy is mainly dissipated in the on-going macro-crack. Somehow, some micro-cracks are still generated leading to a slight increase in $V_{F P Z}$.

- Phase III where an horizontal plateau is present in the post-peak region. This horizontal plateau means that $V_{F P Z}$ does not increase and is stabilized. It is because the fracture energy is dissipated in the existing macro-crack. This plateau appears at about $85 \%$ of post-peak loading.

These three phases are also observed in the experimental work of Alam et al. [19] for the 


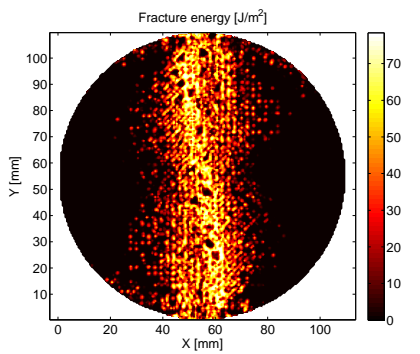

(a) $S_{1}$

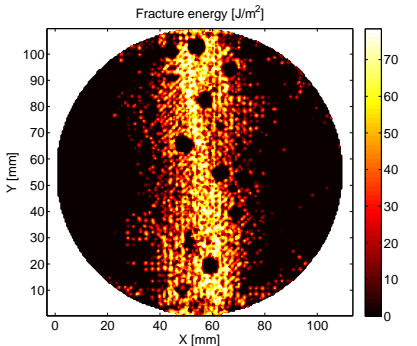

(b) $S_{2}$

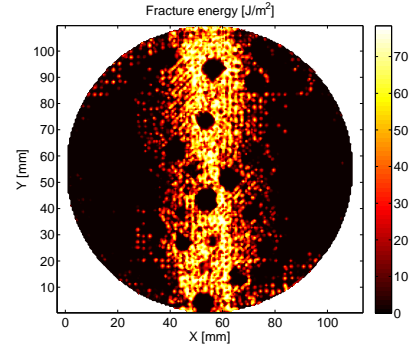

(c) $S_{3}$

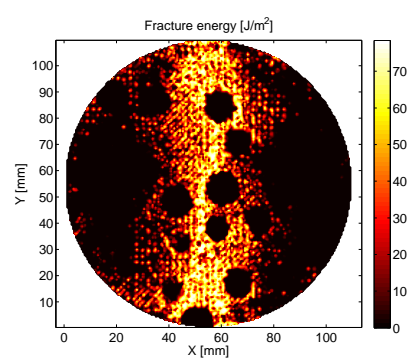

(d) $S_{4}$

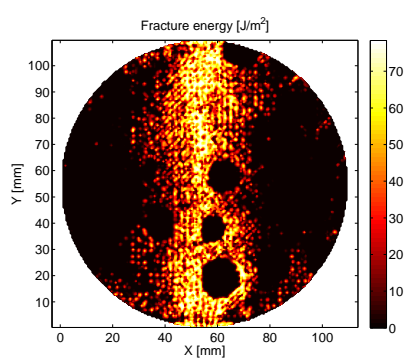

(e) $S_{5}$

Figure 13: 2D fracture energy $\left[\mathrm{J} \cdot \mathrm{m}^{-2}\right]$ for $D=4,8,10,14$ and $16 \mathrm{~mm}$ in cylinder slices located at $Z=25$ $m m$ at the end of the computation

fracture analysis of notched beams by means of DIC an AE. They also find that at about $80 \%$ of post-peak loading, the FPZ evolution is stabilized.

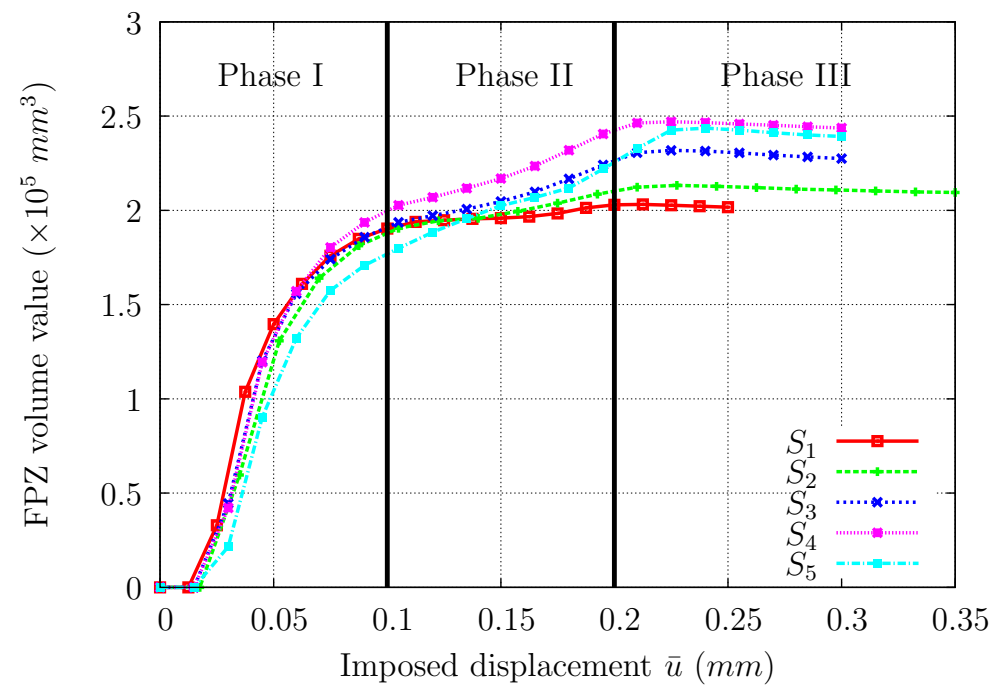

Figure 14: Evolution of $V_{F P Z}$ in relation with the imposed displacement for $D=4,8,10,14$ and $16 \mathrm{~mm}$ 
Finally, the correlation between the increase in micro-cracks density and $V_{F P Z}$ is illustrated in Fig. 15. This plot superimposes the cumulative micro-cracks density $\rho_{m c}$ and $V_{F P Z}$ in relation with the imposed displacement for $D=10 \mathrm{~mm}$. We note $n_{m c}$ the number of micro-cracks. It is important to stress the fact that the representation of the cumulative micro-cracks density $\rho_{m c}$ is used as a similar tool as the accoustic events measured in the experimental work of Alam et al. [19]. They both explain the cracking process (from diffuse cracks to localized crack) with information coming from the fine scale.

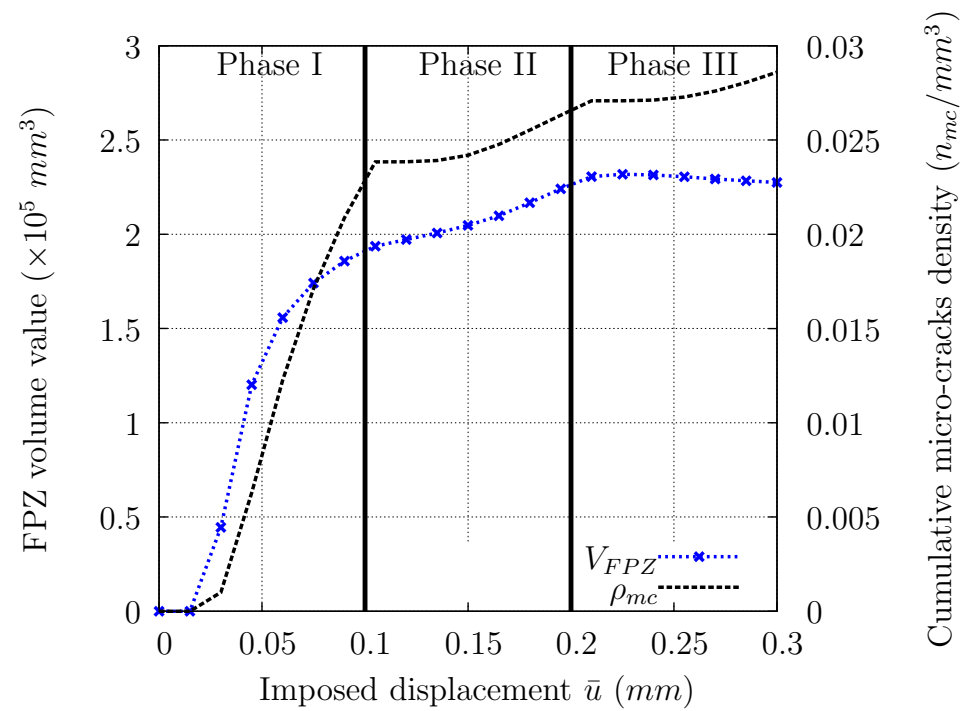

Figure 15: Evolution of $V_{F P Z}$ and $\rho_{m c}$ in relation with the imposed displacement for $D=10 \mathrm{~mm}$

Fig. 16 plots the relation between the FPZ volume value and the FPZ width value. We note a linear relation. Consequently, the FPZ width value can also be regarded to study the FPZ evolution.

Regarding computations conducted in this paper, it is relevant to wonder if the computed results are statically representative. Indeed as stated in Grassl et al. [30] and observed in Fig. 19 for tensile fracture, the cracking process, - starting from micro-cracks nucleation to macro-crack formation -, in which most of the energy is dissipated, is predominantly determined by the random arrangement of aggregates. Consequently, the crack paths in concrete subjected to tension will differ significantly. This conclusion implies that a purely deterministic meso-scale model, which does not consider the statistical variation of the 


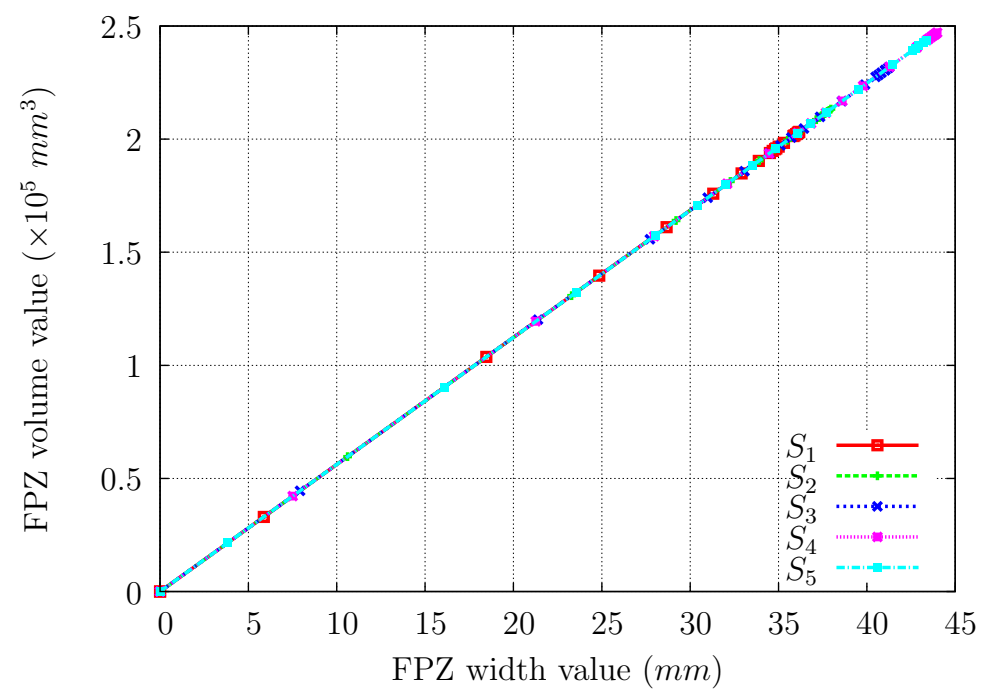

Figure 16: Relation between the FPZ volume value and the FPZ width value After phase I, we observe that the standard deviation increases. The volume of the FPZ begins to be sensitive to the arrangement of the aggregates from the phase II, showing the

\footnotetext{
${ }^{1}$ the number of realizations may appear rather small but regarding the computation time as well as the computational power at the authors disposal, it is quite difficult to perform more realizations within a decent time
} 
interaction between the aggregates and the mortar matrix. The standard deviation then increases sharply at the beginning of phase III. So, the influence of the arrangement of the aggregates (as well as the influence of the size of the aggregates) increases as the imposed displacement increases.As pointed out previously, the characteristics of the FPZ depend not only on the size of the aggregates, but also on their arragement inside the specimen. However, the volume of the FPZ during the phase III must be less sensitive to a random arrangement of the aggregates for small sizes than for large sizes. This implies that to better investigate this phase, the mechanical calculation and the following analysis should be performed on several arrangements randomly created with a number of random arrangements depending on the size of the aggregates. The study of the evolution of the volume of the FPZ for different sizes and arrangement thus shows that the study of the evolution of the volume of th FPZ during the phases I and II can be made on a single random arrangement, whatever the size of the aggregate. These phases are the most important as they correspond to small crack widths and thus are more representative of the behavior of a structure in a natural environment. For the phase III, the results depend on the arrangement for large sizes and a statistical study should be performed. Nevertheless, the present study will be made on the basis of a single arrangement for each size even for the phase III.

\subsubsection{FPZ width value $\left(L_{F P Z}\right)$}

Fig. 18 plots the evolution of $L_{F P Z}$ in relation with the imposed displacement for $D=$ 4, 8, 10, 14 and $16 \mathrm{~mm}$. Considering the fact that the computation of $L_{F P Z}$ is performed with the analysis of the fracture energy (as explained in the introduction of this part), it is relevant to depict the evolution of this fracture energy by means of a 2D representation. For instance, Fig. 19 plots this fracture energy evolution in relation with the imposed displacement for a slice at the middle of the specimen $(Z=25 \mathrm{~mm})$, for $D=10 \mathrm{~mm}$. We can correlate Fig. 19 with the aforementionned phases (I, II, III):

- Phase I corresponds to fig. 19(a) to 19(d). We observe the development of a band where the fracture energy is dissipated. This band can be correlated with $L_{F P Z}$ rises. 


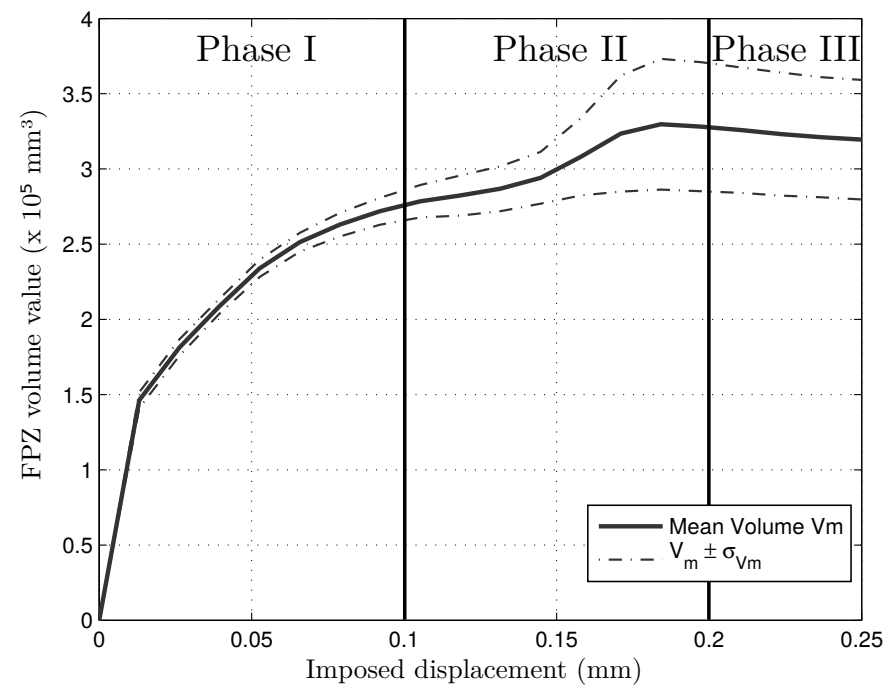

Figure 17: Mean value of $V_{F P Z}$ and range between the mean plus and minus one standard deviation by avering 10 realizations

- Phase II corresponds to fig. 19(e) to 19(g), At the end of this phase, the width of the band where the fracture energy is dissipated is almost stabilized. Nevertheless a narrower band concentring a higher value of the dissipated energy is created (yellow color in the figures with a value close to 70-80 $\mathrm{J}^{-2} \mathrm{~m}^{-2}$. This narrower band is related with the macro-crack formation. In this phase, $L_{F P Z}$ rises slowly.

- Phase III corresponds to fig. 19(h) to $19(\mathrm{j})$. In this phase, the width of the band where the energy is dissipated is stabilized. It can be correlated to the fact that $L_{F P Z}$ presents an horizontal plateau and consequently does not increase anymore.

The numerical values obtained for $L_{F P Z}(35.9,37.8,41.0,43.77$ and $43.18 \mathrm{~mm})$ are in accordance with the experimental results of Alam et al. [19]. In their work, the authors obtain values ranging from 50 to $80 \mathrm{~mm}$.

\subsubsection{FPZ volume (width) evolution versus the aggregate size}

Fig. 20 plots the evolution of the FPZ volume (width) value in relation with the aggregate diameter for $\bar{u}=0.25 \mathrm{~mm}$. The value of the imposed displacement chosen for the plot is 


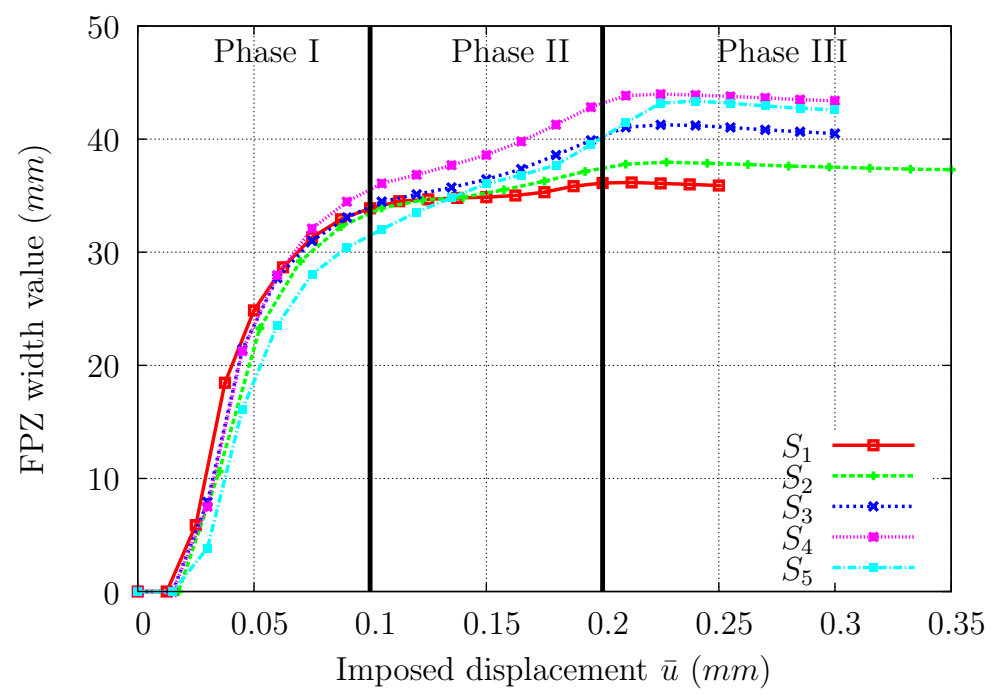

Figure 18: Evolution of the FPZ width value in relation with the imposed displacement for $D=4,8,10$, 14 and $16 \mathrm{~mm}$

such that the set of curves is located in phase III. Consequently, the size of the FPZ is stabilized and comparison can hold. Fig. 20 shows an increasing trend between the FPZ volume (width) value and the aggregate diameter. We can conclude that the FPZ volume (width) is correlated to the aggregate size. This conclusion can also be observed in Fig. 13. We see that the fracture energy is mainly dissipated in a band whose width increases with the aggregate diameter.

These results are also in accordance with the experimental work of Otsuka and Date [17]. Even if it is for the FCZ (Fracture Core Zone) - defined as the volume of the specimen inside which $70 \%$ of the total fracture energy is dissipated-, they show an increase in the width of the FCZ with the increase of the maximum aggregate size.

\section{Conclusion}

In the present work, a meso-scale analysis of the tensile splitting test was used to investigate the size effect on the nominal stress at failure $\sigma_{N}$ and to determine the fracture process zone of concrete, which is defined as the volume of the specimen inside which $95 \%$ of the total fracture energy is dissipated. The study resulted in the following conclusions: 


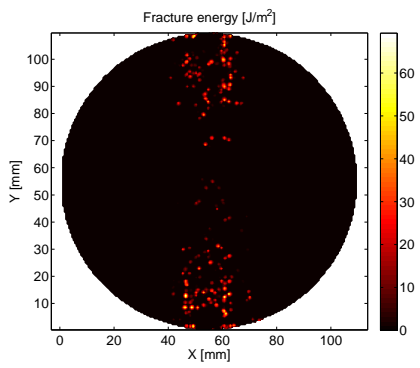

(a) $\bar{u}=0.03 \mathrm{~mm}$

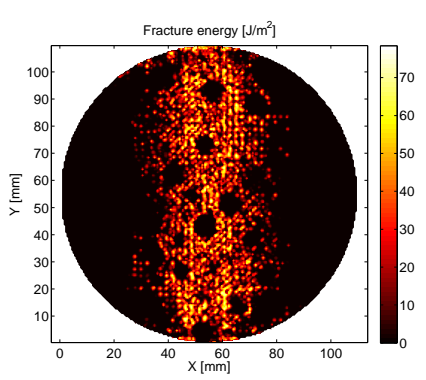

(d) $\bar{u}=0.105 \mathrm{~mm}$

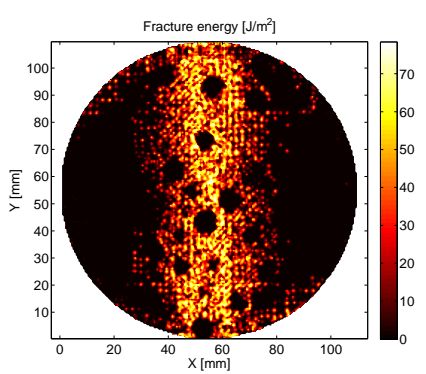

(g) $\bar{u}=0.21 \mathrm{~mm}$

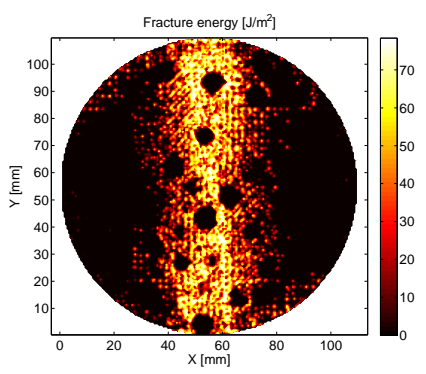

(j) $\bar{u}=0.3 \mathrm{~mm}$

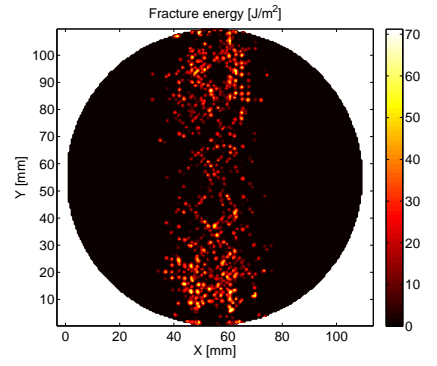

(b) $\bar{u}=0.045 \mathrm{~mm}$

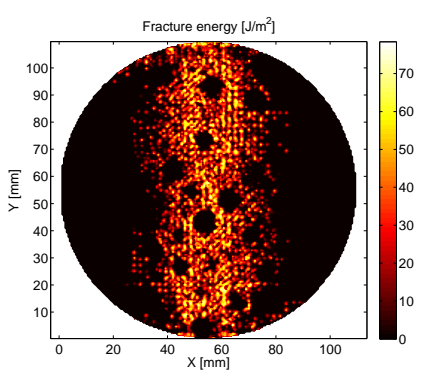

(e) $\bar{u}=0.12 \mathrm{~mm}$

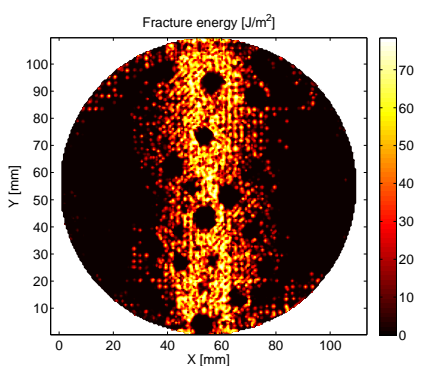

(h) $\bar{u}=0.225 \mathrm{~mm}$

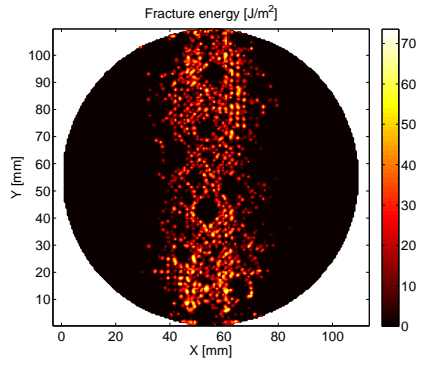

(c) $\bar{u}=0.06 \mathrm{~mm}$

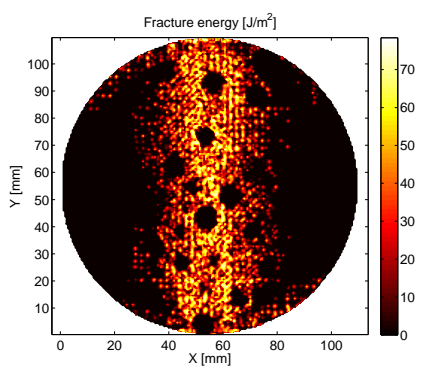

(f) $\bar{u}=0.18 \mathrm{~mm}$

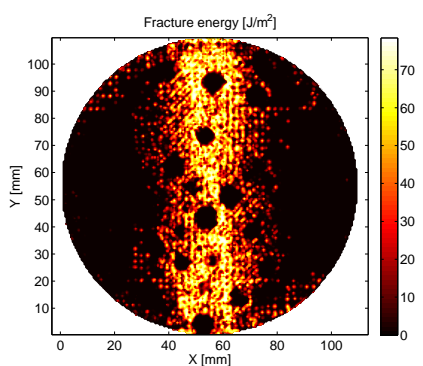

(i) $\bar{u}=0.285 \mathrm{~mm}$

Figure 19: 2D fracture energy evolution $\left[\mathrm{J}^{-2}\right]$ in relation with the imposed displacement for $D=10 \mathrm{~mm}$ in a cylinder slice located at $Z=25 \mathrm{~mm}$ 


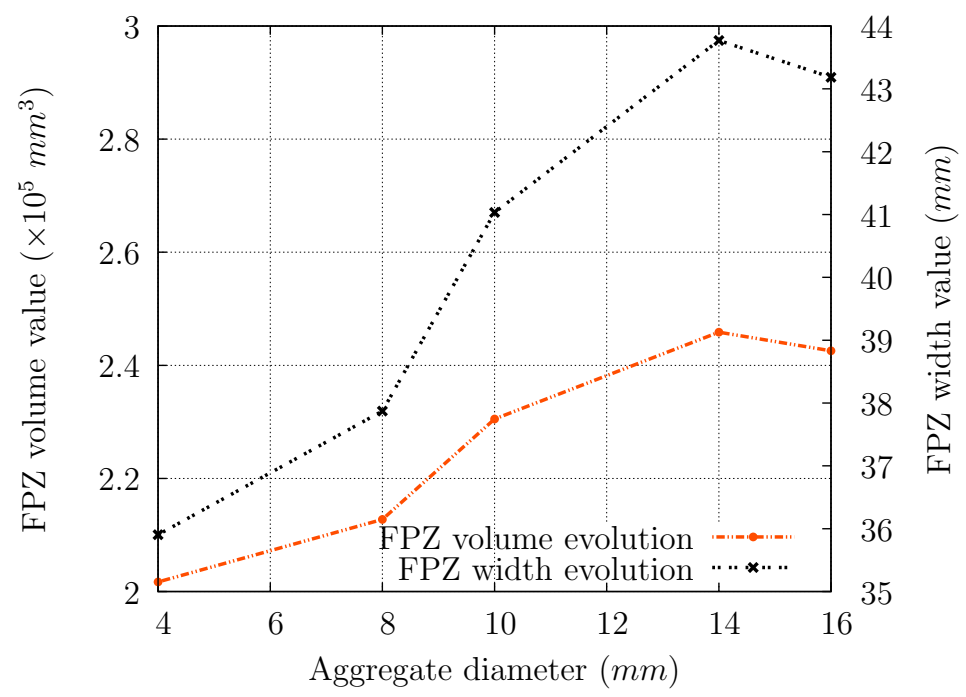

Figure 20: Evolution of the FPZ volume (width) value in relation with the aggregate size $D=4,8,10,14$ and $16 \mathrm{~mm}$ for $\bar{u}=0.25 \mathrm{~mm}$

1. The size effect on the nominal stress at failure $\sigma_{N}$ can be investigated by increasing the aggregate size instead of the specimen size considering a modified form of the Bažant size effect law.

2. The fracture process zone evolution can be divided into three phases in relation with the cracking process. The volume and the width of the fracture process zone increase rapidly in the post-peak at rupture region (Phase I). The rate of increase is slowed down in the peak at rupture region (Phase II) and is stabilized in the post-peak at rupture region (Phase III).

3. The volume and the width of the fracture process zone increase with the aggregate size.

In the future works, mesoscale model results coupled to the fracture energy analysis method will be used to calibrate non-local macroscopic damage models (see for instance Pijaudier-Cabot and Bažant, [53]). Indeed, the characteristic length parameter of these models have been shown to be related to the width of the fracture process zone (see Grassl et al. [30] or point 4 of the conclusion of [53]). In addition, even 3D non-local macroscopic models could be calibrated regarding the fact that the volume of the FPZ is also calculated. 
Last but not least, advanced macroscopic models such as the Thick Level Set model (see Moes et al. [54]) with the following key-points:

- damage model with a non-locality treatment by means of a length scale,

- possibility of transition from damage to fracture,

could also be calibrated and applied to the study of the tensile splitting test at the macroscopic scale.

\section{References}

[1] N. Lundborg, The strength-size relation of granite, International Journal of Rock Mechanics and Mining Sciences and Geomechanics Abstracts 4 (3) (1967) 269-272.

[2] G. Sabnis, S. Mirza, Size effects in model concretes ?, Journal of the Structural Division 105 (6) (1979) $1007-1020$.

[3] T. Hasegawa, T. Shioya, T. Okada, Size effect on splitting tensile strength of concrete, Proceedings, Japan Concrete Institute 7 th Conference, 309-312, June 1985.

[4] W. F. Chen, R. L. Yuan, Tensile strength of concrete: Double-punch test, Journal of the Structural Division 106 (8) (1980) 1673-1693.

[5] C. Ross, P. Thompson, J. Tedesco, Split-hopkinson pressure-bar tests on concrete and mortar in tension and compression, ACI Materials Journal 86 (5) (1989) 475-481.

[6] Z. Bažant, Size effect in blunt fracture: Concrete, rock, metal, Journal of Engineering Mechanics 110 (4) (1984) 518-535.

[7] T. Tang, S. Shah, C. Ouyang, Fracture mechanics and size effect of concrete in tension, Journal of Structural Engineering 118 (11) (1992) 3169-3185.

[8] Z. Bažant, A. Yavari, Is the cause of size effect on structural strength fractal or energetic-statistical ?, Engineering Fracture Mechanics 72 (1) (2005) 1-31.

[9] Z. Bažant, M. Taghi Kazemi, T. Hasegawa, J. Mazars, Size effect in brazilian split-cylinder tests: Measurements and fracture analysis, ACI Materials Journal 60 (3) 325-332.

[10] J. Kim, S.-H. Eo, H.-K. Park, Size effect in concrete structures without initial crack, Fracture Mechanics: Application to concrete 118 (1990) 179-196.

[11] A. Carpinteri, B. Chiaia, G. Ferro, Size effects on nominal tensile strength of concrete structures: multifractality of material ligaments and dimensional transition from order to disorder, Materials and Structures 28 (6) (1995) 311-317. 
[12] Z. Bažant, Fracture energy of heterogeneous materials and similitude, in: S. Shah, S. Swartz (Eds.), Fracture of Concrete and Rock, Springer New York, 1989, pp. 229-241.

[13] M. Sutton, W. Wolters, W. Peters, W. Ranson, S. McNeill, Determination of displacements using an improved digital correlation method, Image and Vision Computing 1 (3) (1983) 133-139.

[14] D. Corr, M. Accardi, L. Graham-Brady, S. Shah, Digital image correlation analysis of interfacial debonding properties and fracture behavior in concrete, Engineering Fracture Mechanics 74 (1-2) (2007) 109121, fracture of Concrete Materials and Structures.

[15] F. Hild, S. Roux, D. Bernard, G. Hauss, M. Rebai, On the use of 3D images and 3D displacement measurements for the analysis of damage mechanisms in concrete-like materials.

[16] C. Oliver-Leblond, A. Delaplace, F. Ragueneau, Modelling of three-dimensional crack patterns in deep reinforced concrete structures, Engineering Structures 83 (2015) 176-186.

[17] K. Otsuka, H. Date, Fracture process zone in concrete tension specimen, Engineering Fracture Mechanics 65 (2-3) (2000) 111-131.

[18] E. Landis, Micromacro fracture relationships and acoustic emissions in concrete, Construction and Building Materials 13 (1-2) (1999) 65-72.

[19] S. Alam, J. Saliba, A. Loukili, Fracture examination in concrete through combined digital image correlation and acoustic emission techniques, Construction and Building Materials 69 (2014) $232-242$.

[20] J. Saliba, A. Loukili, F. Grondin, J.-P. Regoin, Experimental study of creep-damage coupling in concrete by acoustic emission technique, Materials and Structures 45 (9) (2012) 1389-1401.

[21] K. Haidar, G. Pijaudier-Cabot, J. Dub, A. Loukili, Correlation between the internal length, the fracture process zone and size effect in model materials, Materials and Structures 38 (2) (2005) 201-210.

[22] E. Schlangen, J. G. M. van Mier, Simple lattice model for numerical simulation of fracture of concrete materials and structures, Materials and Structures 25 (1992) 534-542.

[23] P. Wriggers, S. O. Moftah, Mesoscale models for concrete: Homogenisation and damage behaviour, Finite Elements in Analysis and Design 42 (2006) 623-636.

[24] N. Benkemoun, M. Hautefeuille, J.-B. Colliat, A. Ibrahimbegovic, Modeling heterogeneous materials failure: 3D meso-scale models with embedded discontinuities, International Journal of Numerical Methods in Engineering 82 (2010) 1671-1688.

[25] N. Benkemoun, A. Ibrahimbegovic, J.-B. Colliat, Anisotropic constitutive model of plasticity capable of accounting for details of meso-structure of two-phase composite material, Computers and Structures 90 (91) (2012) 153-162.

[26] R. Pedersen, A. Simone, L. Sluys, Mesoscopic modeling and simulation of the dynamic tensile behavior of concrete, Cement and Concrete Research 50 (2013) 74-87.

[27] E. Roubin, A. Vallade, N. Benkemoun, J.-B. Colliat, Multi-scale failure of heterogeneous materials: A 
double kinematics enhancement for embedded finite element method, International Journal of Solids and Structures 52 (2015) 180-196.

[28] X. Jourdain, J. Colliat, C. De Sa, F. Benboudjema, F. Gatuingt, Upscaling permeability for fractured concrete: mesomacro numerical approach coupled to strong discontinuities, International Journal for Numerical and Analytical Methods in Geomechanics 38 (5) (2014) 536-550.

39] E. Schlangen, E. J. Garboczi, Fracture simulations of concrete using lattice models: computational aspects, Engineering Fracture Mechanics 57 (1997) 319-332.

[40] M. Yip, J. Mohle, J. E. Bolander, Automated modeling of three-dimensional structural components using irregular lattices, Computer-Aided Civil anf Infrastructure Engineering 120 (2005) 393-407. 
[41] A. Lachihab, K. Sab, Aggregate composites: a contact based modeling, Computational Material Science 33 (2005) 467-490.

[42] M. Ortiz, Y. Leroy, A. Needleman, A finite element method for localized failure analysis, Computer Methods in Applied Mechanics and Enginnering 61 (1987) 189-214.

[43] J. Simo, J. Oliver, F. Armero, An analysis of strong discontinuities induced by strain-softening in rate independent inelastic solids, Computational Mechanics 12 (1993) 277-296.

[44] J. Simo, M. Rifai, A class of mixed assumed strain methods and the method of incompatible modes., International Journal of Numerical Methods in Engineering 29 (1990) 1595-1638.

[45] C. Felippa, On the original publication of the general canonical functional of linear elasticity, Journal of Applied Mechanics 67/1 (2000) 217-219.

[46] H.-C. Hu, On some variational methods on the theory of elasticity and the theory of plasticity, Scienca Sinica 4 (1955) 33-54.

[47] K. Washizu, On the variational principles of elasticity and plasticity Aeroelastic and Structures Research Laboratory, Technical Report 25-18, MIT, Cambridge, 1955.

[48] B. Fraeijs de Veubeke, Variational principles and the patch test, International Journal of Numerical Methods in Engineering 8 (1974) 783-801.

[49] J. Simo, T. Hughes, Computational Inelasticity, Interdisciplinary Applied Mathematics, Springer Verlag, New York, Berlin, Heidelberg, 1997.

[50] E. Wilson, The static condensation algorithm, International Journal for Numerical Methods in Engineering 8 (1974) 198-203.

[51] Q. Li, Z. Deng, H. Fu, Effect of aggregate type on mechanical behavior of dam concrete, ACI materials journal 1016 (2004) 483-492.

[52] H. Mihashi, N. Nomura, M. Izumi, Fracture of concrete and rock, in: S. Shah, S. Swartz, B. Barr (Eds.), Influence of matrix strength and gravel size on fracture properties of concrete, Elsevier, 1989, pp. 503-512.

[53] G. Pijaudier-Cabot, Z. Bažant, Nonlocal damage theory, Journal of Engineering Mechanics 113 (10) (1987) 1512-1533.

[54] N. Moës, C. Stolz, P.-E. Bernard, N. Chevaugeon, A level set based model for damage growth: the thick level set approach, International Journal for Numerical Methods in Engineering 86 (3) (2011) $358-380$. 